\title{
Study on the Development of Urban Farms Promoting Children's Labor education
}

\author{
Dongfu Ma \\ North China Electric Power University (Baoding), Hebei, China \\ 2720247914@qq.com
}

\begin{abstract}
Labor is a natural property of children, the development of urban farms to create a good artificial natural space in the tumult of the city. This article will conduct research on the development of the advantages of urban farms, its status quo and future development mode.
\end{abstract}

Keywords: children; urban farm; labor education; parent-child activities.

\section{Introduction}

The new Outline points out that, "Environment is an important educational resource, and should be created and utilized to effectively promote the development of young children." Agricultural knowledge and labor education is playing an important role in improving children's identity ability and forming good social values [1]. In the past decades, most Chinese people were still living rural conditions. They had a comprehensive knowledge about agriculture in the simple daily field work. At present when China is undergoing a rapid urbanization, how to spread agricultural knowledge to children has become a problem. To develop urban farms will help to solve the problem of labor education of children within the city [2].

\section{The Background and significance of the study}

As the society develops, it has increasingly higher demands for people, including a sound personality, good intelligence, excellent creative ability and dedication ability to community service. However, a person without high labor ability, self-care ability, practical ability and creative ability cannot adapt to the development of society and will be ruthlessly eliminated. Therefore, we have to cultivate this ability from an early age, so as to conform to the trend of the times. In 1982, the chief architect - Comrade Deng Xiaoping, stressed that "education should start with children." As new-born energy of national construction, children have a bearing on the future of national development, and good education for children is of long-term significance to the society. Marx and Engels had also urged people to cultivate themselves comprehensively to be able to work with both mind and labor, and but labor education has been playing a powerful role in children's quality education. Labor education can promote children to gain good moral quality, to develop respect for the fruits of labor and to form thrift habits. Besides, it helps to train children to be hard in work and to overcome difficulties. Moreover, it could develop children's intelligence, imagination and creativity and improve children's practical ability. Finally, it is conducive to cultivating healthy personality and developing a sense of responsibility to family and society.

Now that the socio-economic is growing and the state is carrying out the comprehensive two-child policy, there will be 16 million newly-born babies in China each year. However, the rapid urbanization has brought lots of high-rise buildings around the city. It has become increasingly difficult for children to gain access to the countryside and fields, and they don't know any knowledge about labor and crops any knowledge. Authors had once investigated a number of children by asking them "how do potato grow up?" and their answers were "I do not know", "they grow from the tree," and other absurd ones. Although, each city has a so-called eco-park, actually children cannot get a good labor education in the park. Thus, solving this problem has become a top priority. 
Then, the author proposes the concept of urban farms. As agricultural bases in urban areas, urban farms combine traditions with modern elements to provide palaces where labor education can be carried out for children. They are of great progressive significance (Figure 1).

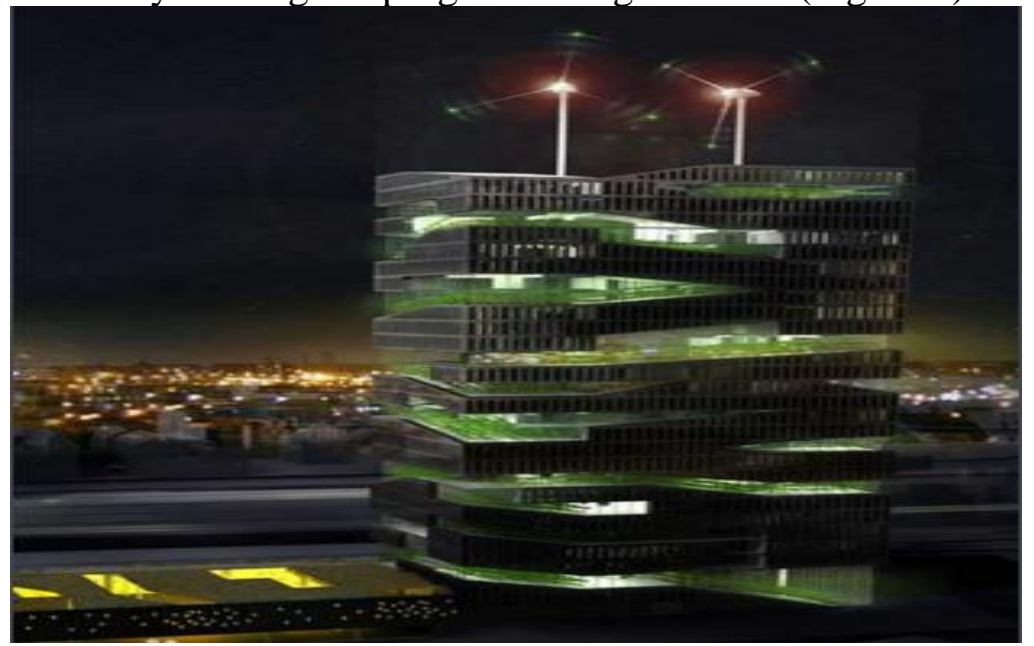

Figure 1 City farms

\section{Development mode of urban farms}

Urban farms incorporate into 3D agriculture. The latter refers to the 3D planting, 3D cultivating or 3D growing agricultural management mode which combines different biological creatures in one place to realize multi-species coexistence, multi-level configuration and multi-level energy recycling by taking advantage of interrelation of creatures, so as to increase interests and remove all evils as well as make full use of space. In terms of the academic term of 3D agriculture, in the early 20th century, Columbia University J.R. Professor Smith had summarized it as follows: three-dimensional agriculture is a comprehensive management mode integrating farming, animal husbandry and processing organically. It is different from the traditional one, because it has retained the traditional one, while combing with modern technology. It is an optimized and efficient agricultural structure utilizing time, space and functions systematically [3].

This combination will bring tremendous advantages which will be reflected in all aspects. Firstly, it offers a rational distribution of vertical type, unit type and network type for three-dimensional urban farms [4], which can significantly improve the utilization of land. Besides, the structure can be set up in the tower and the light and nutrition for plant can be solved via technologies completely. The rational labor management can significantly shorten the growth cycle of a plant, as well as produce a lot of products. This model does not take up too much land, which is just in line with the urban land shortage. Secondly, because urban farms are established in the city, the output of agricultural products can be consumed without transportation, which has not only guaranteed the freshness of the product, but also reduced the long-distance transport of goods and other processes. Thirdly, this mode will bring the public to participate in the production activities, so that consumers can monitor the production process, while promoting the sales, catering, tourism and other services.

\section{Taking advantage of urban farms to develop children's labor education}

Urban farm is rooted in the city. Coupled with several above-mentioned advantages, it has an immeasurable effect on the development children's labor education.

The national family-school integration educational expert and the state registered counselor Wang Libo once proposed in the lecture that, "A survey shows that in 2020 there will be a peak of Chinese adolescent's mental disease. Therefore, to enhance parent-child education and improve family relations situation are urgent tasks!" Parent-child education emphasizes the integration of social training, education knowledge, ability, quality, as well as character and emotion, rather than the mere knowledge transfer. Thus, it differs from traditional parenting education in kindergarten, because it 
focuses more on the interaction of parents and children in the game, so as to enhance the feelings between family members. Meanwhile, the child could gain a good physical and mental development in the process. As a new thing in the city, urban farm has the biggest feature by creating a venue very close to the nature, so that family members can fully interact in the near-natural environment. For example, farms can provide venues for them to pick up fruits, understand and appreciate ornamental plantings, and to cook family meals. In these conditions, children and parents can master a large number of agricultural knowledge their joint working. Besides, it will also cultivate their labor interests and form good parent-child relations, which is more conducive to set up a harmonious and happy family (Figure 2).

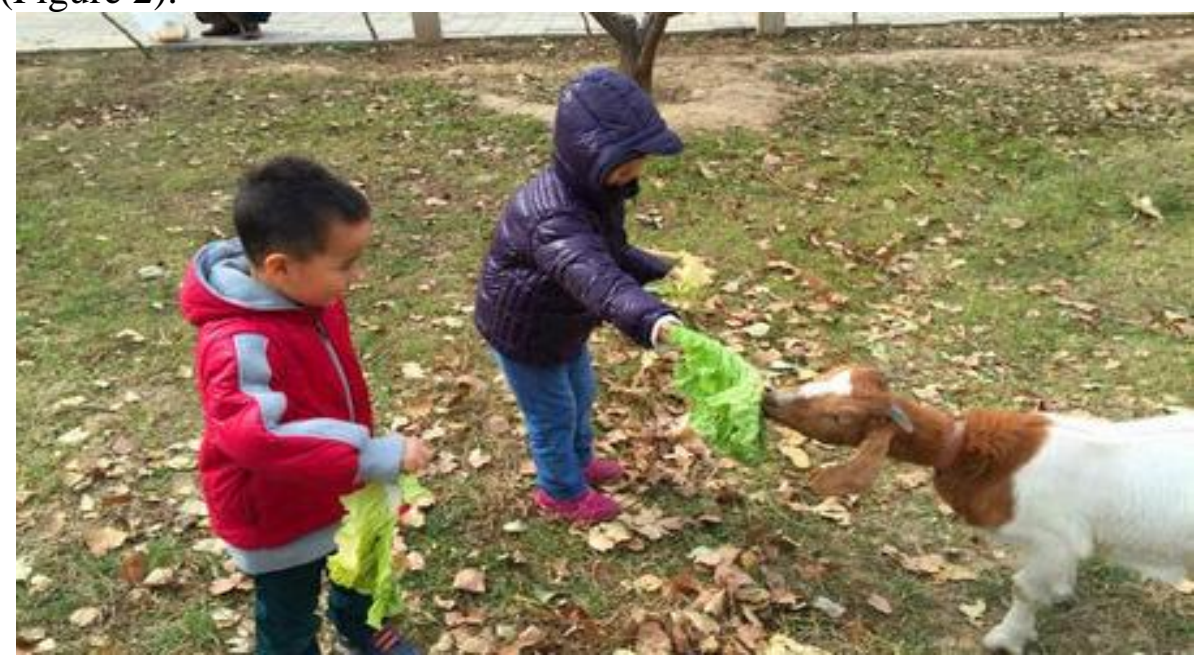

Figure 2 Close to nature

Today, education tends to develop toward diverse directions. Thus, the society has constantly increased its requirements for people. Companies are particularly focusing on personnel's innovation and practical ability. However, those abilities are not born, but acquired in the education. In the city towering with high-rise buildings, the emergence of urban farms will provide a good venue for the education. Thus, they will be able to work as a base for quality education and cooperate with kindergartens, primary schools and other projects to open specialized activity courses for children. This will not only increase the farm income, but also improve the ability of the child's practical ability, thus contributing to the child's physical and mental development.

\section{Conclusion}

Children's labor education is very important. Urban farms are new projects in the new century. They will certainly achieve progress gradually, and their labor education effect on children will be growing by each passing day, so that we can make more effort to research this area.

\section{References}

[1] Zhao Ronghui. Labor is the Nature of Children. Monthly Educational Academy, 2009 (11).

[2] Liu Guoqi. On cultivation of children's good work habits. The national teacher's Eleven-Five scientific research funds stage set (volumes in Hunan province), 2010.

[3] Huang Yibin, Ke Binan, Chen En,et al. Research and practice of sightseeing ecologic agriculture--Longhai longjia eco-village in Fujian province as an example. Agriculture and garden economy, 2005.

[4] Luo Qingping, Zhouchao. Exploration on the Future Green Urban Living Conditions - A Case Study of Beijing Consideration on in the Process of 798 Art District Urban 3D Farm Design and Competition. Architecture in Central China term in August, 2013. 